2004s-35

\title{
Advertising and Coordination in Markets with Consumption Scale Effects
}

\author{
C. Robert Clark, Ignatius J. Horstmann
}

Série Scientifique
Scientific Series

Montréal
Mai 2004

(C) 2004 C. Robert Clark, Ignatius J. Horstmann. Tous droits réservés. All rights reserved. Reproduction partielle permise avec citation du document source, incluant la notice $\mathbb{C}$.

Short sections may be quoted without explicit permission, if full credit, including (C) notice, is given to the source.
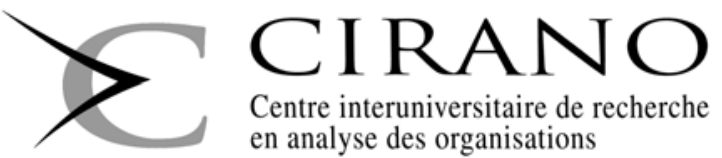

Centre interuniversitaire de recherche en analyse des organisations 


\section{CIRANO}

Le CIRANO est un organisme sans but lucratif constitué en vertu de la Loi des compagnies du Québec. Le financement de son infrastructure et de ses activités de recherche provient des cotisations de ses organisations-membres, d'une subvention d'infrastructure du ministère de la Recherche, de la Science et de la Technologie, de même que des subventions et mandats obtenus par ses équipes de recherche.

CIRANO is a private non-profit organization incorporated under the Québec Companies Act. Its infrastructure and research activities are funded through fees paid by member organizations, an infrastructure grant from the Ministère de la Recherche, de la Science et de la Technologie, and grants and research mandates obtained by its research teams.

\section{Les organisations-partenaires / The Partner Organizations}

PARTENAIRE MAJEUR

. Ministère du développement économique et régional et de la recherche [MDERR]

PARTENAIRES

. Alcan inc.

. Axa Canada

. Banque du Canada

. Banque Laurentienne du Canada

. Banque Nationale du Canada

. Banque Royale du Canada

. Bell Canada

. BMO Groupe Financier

. Bombardier

. Bourse de Montréal

. Caisse de dépôt et placement du Québec

. Développement des ressources humaines Canada [DRHC]

. Fédération des caisses Desjardins du Québec

. GazMétro

. Hydro-Québec

. Industrie Canada

. Ministère des Finances du Québec

. Pratt \& Whitney Canada Inc.

. Raymond Chabot Grant Thornton

. Ville de Montréal

. École Polytechnique de Montréal

. HEC Montréal

. Université Concordia

. Université de Montréal

. Université du Québec à Montréal

. Université Laval

. Université McGill

. Université de Sherbrooke

AssociE A :

. Institut de Finance Mathématique de Montréal $\left(\right.$ IFM $\left.^{2}\right)$

- Laboratoires universitaires Bell Canada

. Réseau de calcul et de modélisation mathématique $\left[\mathrm{RCM}^{2}\right]$

. Réseau de centres d'excellence MITACS (Les mathématiques des technologies de l'information et des systèmes complexes)

Les cahiers de la série scientifique $(\mathrm{CS})$ visent à rendre accessibles des résultats de recherche effectuée au CIRANO afin de susciter échanges et commentaires. Ces cahiers sont écrits dans le style des publications scientifiques. Les idées et les opinions émises sont sous l'unique responsabilité des auteurs et ne représentent pas nécessairement les positions du CIRANO ou de ses partenaires.

This paper presents research carried out at CIRANO and aims at encouraging discussion and comment. The observations and viewpoints expressed are the sole responsibility of the authors. They do not necessarily represent positions of CIRANO or its partners. 


\title{
Advertising and Coordination in Markets with Consumption Scale Effects"
}

\author{
C. Robert Clark $k^{\dagger}$ Ignatius J. Horstmann ${ }^{\ddagger}$
}

\begin{abstract}
Résumé / Abstract
Il existe plusieurs produits à la fois bien établis et à qualité comparable, qui font l'objet de campagnes publicitaires coûteuses. Toutefois, l'explication usuelle avancée pour justifier la publicité coûteuse pour ces produits, c'est-à-dire le fait qu'elle permette aux firmes de faire connaître la qualité de leurs produits, ne correspond aucunement à cette situation. Dans ce papier, nous développons un modèle de publicité basé sur l'idée suivante : l'utilité qu'un consommateur retire d'un produit peut dépendre aussi du nombre de consommateurs qui achètent également le même produit. Nous montrons dans ce cas que les firmes peuvent utiliser des messages publicitaires pour inciter les consommateurs à consommer le même produit et ce, même si les dépenses publicitaires ne sont pas observables. Dans notre modèle, un consommateur qui n'observe pas de message publicitaire pour un produit quelconque croira que ce même produit a probablement peu de valeur; par conséquent, à l'équilibre, les firmes se serviront de messages publicitaires pour éviter ces croyances négatives de la part des consommateurs. Par ailleurs, notre modèle génère des prédictions sur les activités de publicité, les parts de marché et les profits qui sont cohérents avec le comportement observé. Notre modèle, contrairement aux modèles de coordination existants dans la littérature, prédit également des prix stables et des séries chronologiques de parts de marché qui correspondent aux observations disponibles sur les produits qui font l'objet de compagnes publicitaires.
\end{abstract}

Mots clés : publicité, coordination, croyances.

Many heavily advertised consumer products are both well established and have no obvious quality variation. A signaling explanation for advertising in these product categories is therefore not compelling. In this paper we develop a model of firm advertising based on the notion that consumer valuations of different products may depend on the number of individuals purchasing each. We show that firms can use advertising to coordinate consumer purchases in such cases, even if advertising levels are unobservable. Failure to see an ad for a product leads consumers to believe that the product is likely low value and firms advertise to avoid these negative beliefs. We show that the model can generate predictions on advertising, market share and profitability that are consistent with observed behavior. The model also generates the stable prices and market share time series behavior observed for advertised consumer products and that existing coordination models fail to provide.

Keywords: advertising, coordination, beliefs.

\footnotetext{
${ }^{*}$ We thank Arthur Robson, Hari Govindan, Peter Streufert and Kyle Bagwell for helpful comments and suggestions.

† Institute of Applied Economics, HEC Montreal, email: robert.clark@hec.ca.

+ Rotman School of Management and Institute for Policy Analysis, University of Toronto.
} 


\section{Introduction}

In the year 2000 firms spent an estimated US $\$ 244$ billion, or approximately $2.5 \%$ of U.S. gross domestic product, advertising their products in the United States. ${ }^{1}$ Measured advertising expenditures for just four product groups, cigarettes ( $\$ 312.8$ million), beer ( $\$ 554.3$ million), soft drinks ( $\$ 604.2$ million) and "fast-food burger restaurants" ( $\$ 1.512$ billion), accounted for more than $1 \%$ of this total and more than $2.5 \%$ of total measured advertising. Within each of these four groups, Philip Morris spent over $\$ 93$ million advertising Marlboro cigarettes, Anheuser-Busch about $\$ 159$ million advertising Budweiser beer, the Coca-Cola Company $\$ 207$ million advertising Coke Classic and McDonald's almost \$665 million advertising its burger chains. A year earlier, the three major credit card companies, Visa International (\$200.2 million), Amex (\$197.6 million) and MasterCard International (\$174.2 million) spent $\$ 372$ million advertising just their credit cards. Manufacturers of bottled water spent over $\$ 52$ million in 2001 and almost $\$ 77$ million in 2002 advertising their products, while makers of athletic shoes spent over $\$ 300$ million in both 1996 and 1997 on advertising their shoes. By the year 2000, Nike was spending over $\$ 600$ million advertising its line of athletic wear.

Since the seminal paper by Nelson (1974), economists have largely understood advertising expenditures as serving an informational role, either providing direct information on the product's existence and price or being indirectly informative about the product's quality the signaling role. The Nelson hypothesis has appeal as an explanation for advertising of new or unfamiliar products and of products for which there is clear quality differentiation

\footnotetext{
${ }^{1}$ This estimate and subsequent ad expenditures come from Leading National Advertisers, a publication of Advertising Age. Website: www.adage.com. Advertising Age collects advertising expenditures by product in 13 media categories representing consumer oriented media with either national or major city exposure. These expenditures constitute measured advertising. In addition Advertising Age constructs estimates of expenditures on things such as direct mailing, promotions and special events and advertising in business publications. These expenditures constitute unmeasured advertising. The total advertising number reported is the sum of measured and unmeasured advertising expenditures.
} 
about which some consumers are persistently uninformed. Empirical studies provide weak support for a quality signaling role for advertising in these cases. ${ }^{2}$ Many of the most heavily advertised products, including all of the ones listed above, do not easily fit into either of these categories, however. Invariably, the most heavily advertised products are well established ones; moreover, in many cases there is no obvious quality dimension on which the products vary. Products such as beer, soft drinks and bottled water are perennial candidates for blind taste tests and, in those tests, consumers are notoriously unable to distinguish one from the other. For advertising of these and many other products, one is compelled to look elsewhere for an explanation.

The explanation we offer in this paper for advertising of products such as the above focuses on advertising's role as a coordination device. Our analysis builds on the insight first provided by Bagwell and Ramey (1994) in the context of retail market advertising. ${ }^{3}$ For our purposes, the credit card market serves as a useful illustration of the coordination problem. An important characteristic of a credit card is the number of retailers that accept the card: the fewer retailers that accept a particular card, the less useful/valuable is the card. Whether or not a given retailer accepts a particular card must depend on, among other things, how many of the retailer's customers use that card. A coordination problem ensues: If few consumers use a given card, few retailers will choose to accept the card, making the card not especially valuable and thereby supporting the consumer decision not to adopt the card. If many consumers use a particular card, many retailers will choose to accept the card, making the card valuable and thereby supporting the consumer decision to adopt.

More generally, a coordination problem exists for any product with the feature that the value that an individual obtains from consuming the product depends on the number of

\footnotetext{
${ }^{2}$ See Horstmann and MacDonald (2003) for more on empirical tests of the quality signaling hypothesis.

${ }^{3}$ The Bagwell and Ramey model is one in which consumers are uninformed about certain product characteristics and about product price. Price is assumed to be declining in the number of customers a retailer has so that consumers have an incentive to coordinate their shopping at a single retailer. Advertising serves as the coordination mechanism, with consumers shopping at the retailer that advertises the most.
} 
others that also consume it. As in the case of credit cards or software, this dependence may be due to network effects. It may also be for reasons of social standing - people want to wear the "right" clothes and consume the "right" products (see Chwe (1999)) or because complementary services require a large customer base. Advertisements, being observable signals, can play a role in coordinating consumer purchase decisions in cases such as these and so can have value even for "established" products (i.e., products whose existence, characteristics and price are known to consumers) and for products having no obvious quality variation.

Our approach to this coordination role for advertising differs from that of Bagwell and Ramey and of Pastine and Pastine (1999a, 1999b) in an important way. These authors effectively assume that consumers perfectly observe the level of (total dollar expenditure on) advertising for every firm. ${ }^{4}$ In essence, consumers know that in 1999 American Express Co. spent $\$ 2.6$ million less on advertising the American Express card than Visa International spent on advertising the Visa card. The same is true for all other products that a consumer buys. The observed advertising levels are the public signals that consumers use to coordinate purchase decisions: they purchase from the firm with the largest advertising expenditure.

Given that products are advertised in a wide range of media - Advertising Age identifies 13 broad media categories - this assumption is enormously strong and, arguably, unrealistic. To know, for instance, that Visa International spent more on advertising than did Amex, consumers must essentially observe all ads for the two cards in all media that the companies use. The same must be true for all other products that consumers consider purchasing. Our approach, in contrast, is to take the opposite stance and to assume that consumers cannot observe any firm's advertising level (total expenditure) and only observe an individual ad in probability. In this environment, a consumer who does not observe an ad for a particular product cannot conclude that the product is not being advertised - the consumer may

\footnotetext{
${ }^{4}$ The same assumption is made in signaling models of advertising with the exception of Hertzendorf (1993) whose set up allows for the the fact that some consumers may see fewer ads than were sent.
} 
simply not have accessed the media in which ads for the product appear - nor even that the product is being advertised less than some other product for which an ad is observed. In short, advertising generates no publicly observed signals on which all consumers might coordinate purchase decisions.

The specific setting we consider is a duopoly with differentiated products in which a consumer's valuation of a given product depends not just on the product's characteristics and price - all observable - but also on the number of other consumers that purchase the product. Each firm can choose to send advertising messages through some medium to consumers. Any individual consumer either observes a message from a particular firm or does not, with the probability that the consumer observes a message depending on the total number of messages sent. No consumer observes the total number of messages sent by any given firm - no consumer observes a firm's advertising level - nor which, if any, other consumers have observed a message.

Our analysis shows that even if advertising generates no publicly observed signals, the situation that we would argue is the empirically relevant one, ads can still act as a coordination device and so firms do advertise in equilibrium. In this way, our model provides an explanation for the observed advertising of products for which there is no obvious quality differentiation: credit cards, bottled water, soft drinks and the like. Essentially, the explanation is that producers of these types of products advertise because of the negative inferences that consumers not seeing an ad for a particular product draw about the value of that product. A consumer who does not see an ad for firm 2's product, say, but does for firm 1's, attaches greater probability to firm 1's product, the advertised product, having large sales, and so being of higher value, than firm 2's product, the non-advertised product. As a result, this consumer is less likely to purchase firm 2's product. Had this consumer failed to observe an ad for either product, he would value firm 1's product less than in the previous situation and so would be less likely to purchase 1's product than previously. These negative inferences, and consequent purchase decisions, provide the profit incentive for a firm to advertise. 
The equilibrium advertising behavior predicted by our model is broadly consistent with the evidence. Our model predicts, for instance, that within a given product category, say soft drinks, varieties with larger measured advertising expenditures have both larger market share and larger profits. This positive relation between measured advertising and market share is consistent with findings by Chintagunta and Vilcassim (1992) in a study of Coke and Pepsi. Erickson (1992) presents evidence for Miller and Anheuser-Busch that supports both the positive advertising-market share and advertising-profitability relations. For a crosssection of products, our model is also able to generate a positive relation between profits and both measured advertising and the advertising-sales ratio. These result are consistent with numerous cross-sectional studies of advertising, market share and profitability (see Lambin (1976) and Comanor and Wilson (1967, 1974), Porter (1974, 1976)). Porter, in particular, shows that the positive correlation between advertising and profitability is especially strong for what he calls 'convenience goods': low-priced, frequently purchased products such as soft drinks and beer.

If we examine the predictions of our model in more detail, we also find that they are, in various ways, quite different from those of existing coordination models. For instance, existing models have the feature that, within a product category, market share depends only on which product is advertised more. This fact has two implications. One is that the time series for a given variety can have a variety's market share rising even as its advertising expenditures fall; subsequently market share can fall even as advertising expenditures rise, yielding a negative relation between observed market share and advertising expenditures. The other is that changes in advertising expenditures for a given variety have no impact on that variety's market share unless the change causes the variety to become the most heavily advertised one. In this case, small changes in advertising expenditures can induce large shifts in market share. Our model, by contrast, predicts a continuous and strictly positive relation between measured advertising expenditures and market share for all varieties within 
a product class, a finding in concert with that of Erickson in the case of Coke and Pepsi. ${ }^{5}$ The standard coordination approach also has that the price of a variety varies depending on whether or not the variety is the most heavily advertised one. Our model, by contrast predicts that price is stable even as advertising expenditures change. This latter outcome is consistent with the view that, for products like the ones discussed above, competition takes place more through non-price means rather than price. Finally, our model predicts that ad campaigns that are expensive to create, such as ones involving a celebrity endorsement, are run so as to be seen by a large audience. The standard coordination approach would predict the opposite.

The remainder of the paper proceeds as follows. In the next section we describe the model. Section 3 lays out the advertising-coordination process and characterizes general features of an equilibrium. Section 4 describes the features of a symmetric advertising equilibrium and generates predictions about observables in this equilibrium. Section 5 provides a discussion of the results and contrasts them with the standard coordination approach. Proofs of various results are provided in the Appendix.

\section{The Model}

We consider a market in which there are two firms, labelled $i=1,2$, each of which produces a single variety of a differentiated product. For ease of exposition we describe the market with

\footnotetext{
${ }^{5}$ At the moment, there are no careful empirical tests that would allow us to distinguish between the predictions of our model and those of existing models. What evidence exists is at least suggestive of our model's predictions. For instance, Chintagunta and Vilcassim show that over the period 1968-1976 annual real advertising expenditures on Coke declined but continued to exceeded annual real expenditures on Pepsi. Over the same period, Coke lost market share to Pepsi. This outcome is what would be predicted by our model but is inconsistent with the predictions of existing coordination models. The cross sectional results on advertising and market share and on advertising and profitability also support our model's predictions but would be at odds with a zero or declining relation.
} 
a Hotelling type structure, assuming that firm 1's variety is located at the point 0 and firm 2 's variety at the point 1 of the unit interval. The market is populated by a continuum of risk neutral consumers of mass $M$ who are uniformly distributed over the interval. Consumer locations are indexed by $k$. Each consumer purchases one unit of one of the varieties. The value that a consumer derives from the consumption of a unit of brand $i$ is given by $v_{i}$. The cost of purchasing from firm $i$ is $t d+p_{i}$ where $p_{i}$ is the price of variety $i$ and $t d$ is the travel cost for consumer located distance $d$ from firm $i$. The utility that consumer $k$ obtains from purchasing firm 1's variety is given by

$$
U_{1}=v_{1}-p_{1}-t k
$$

and the utility from purchasing firm 2's variety by

$$
U_{2}=v_{2}-p_{2}-t(1-k)
$$

Our analysis differs from the standard Hotelling analysis in that we assume that the value that any consumer obtains from purchasing a unit of a given variety depends on the fraction of the total population also purchasing that variety. For simplicity, we assume that this dependence takes a simple "threshold" structure given by

$$
v_{i}= \begin{cases}\underline{V} & \text { if } n_{i}<\bar{N} \\ \bar{V} & \text { if } n_{i} \geq \bar{N}\end{cases}
$$

Here $n_{i}$ is the fraction of consumers purchasing variety $i$ and $\bar{N}$ is the threshold level of purchases. ${ }^{6}$ We assume that $\bar{V}>\underline{V}$, so that a consumer's utility from purchasing variety $i$ is higher if more than the threshold fraction also purchase $i$. The threshold, $\bar{N}$, is the same for all consumers and both varieties and is greater than $1 / 2$, implying that both firms cannot simultaneously exceed the threshold. These assumptions are intended to capture the

\footnotetext{
${ }^{6}$ Bental and Spiegal (1995) also assume that a network must be of some minimum size in order to be of any use at all.
} 
intuitive idea (particularly intuitive for the case where coordination is for reasons of social standing) that both brands cannot represent the "right" choice. ${ }^{7}$

Consumers simultaneously make purchase decisions, with each consumer purchasing the variety that yields the higher expected utility. We assume that the consumers know the values of $\bar{V}, \underline{V}, \bar{N}$ and both prices at the time of purchase. Expectations are only with respect to which, if either, variety obtains enough purchases to exceed the threshold. ${ }^{8}$ It is these expectations that the firms attempt to influence through advertising activities.

Firms have access to a single advertising technology. This technology communicates a message about a firm's product that any given consumer might either observe or not observe. The message cannot be targeted at specific consumers (i.e., the firm cannot control which consumers observe a message and which do not) and the probability that any given consumer observes a message is the same for all consumers. ${ }^{9}$ These assumptions mean that we can define an advertising rate for firm $i$ by a scalar $a_{i} \in[0,1]$ denoting both the fraction of the population that observes firm $i$ 's message and the probability that any given consumer observes $i$ 's message. While any individual consumer either does or does not observe a message, no consumer observes the advertising rate. This distinction between the observability of a message and the observability of the advertising rate is key. It is meant to capture the notion that, while consumers see ads for a given product, they do not know how many others see the same ads. Because a consumer's utility from purchasing variety $i$ depends on how many others also purchase $i$, the advertising rate can be relevant to any consumer's purchase decision. It is about this rate that the consumer forms expectations; these expectations, naturally, are affected by whether or not the consumer observes a message.

\footnotetext{
${ }^{7}$ This specification is that of a Hotelling-type location framework. The structure imposed here is actually more than what is necessary to prove most of our basic results, including the existence of a symmetric advertising equilbrium. In the appendix we prove all results for the most general specification possible.

${ }^{8}$ This assumption stands in contrast to Bagwell and Ramey (1994a,1994b) where it is assumed that consumers must search to determine prices.

${ }^{9}$ What is being abstraced from here is any notion of the quality of an ad campaign.
} 
For a firm to advertise, it must incur a fixed cost $F>0$ to design its advertising campaign. The firm also incurs a variable cost, $c(a)$, should it advertise at rate $a$. We assume that $c(0)=0$ and that $c(\cdot)$ is increasing and strictly convex. We also normalize costs such that $c^{\prime}(0)=0$. Advertising costs are the same for both firms. Firms also incur a constant unit production cost, normalized to zero. Firms are risk neutral and each chooses a price and advertising rate to maximize expected profits.

The timing of moves is as follows: The firms simultaneously choose a price and advertising rate pair, $\left(p_{i}, a_{i}\right)$. All consumers observe the price choices. A fraction $a_{i}$ of consumers observe a message from firm $i$; none, however observe the advertising rates of either firm. Based on observed prices and messages, each consumer forms beliefs about the probability that a given variety will exceed the threshold. Based on these beliefs, each consumer purchases the variety that yields the higher expected utility. The equilibrium notion is Perfect Bayesian Equilibrium.

\section{Advertising and Coordination}

Because the only function of advertising in the model is to condition consumer beliefs, there is necessarily an equilibrium in which consumers believe that a firm's advertising serves no useful function. In any such equilibrium, the firm chooses not to advertise. What we investigate here is whether, and under what conditions, there are equilibria in which both firms choose to advertise and in which the advertising serves to condition consumer beliefs about the variety that will have purchases beyond the threshold level. These are the equilibria in which advertising serves as a coordination device for consumer purchases. We show that such equilibria generally exist and have features very much consistent with observations in markets with advertising. ${ }^{10}$

\footnotetext{
${ }^{10}$ We have chosen to focus only on equilibria in which both firms advertise, but of course equilibria in which only one firm advertises exist also. We do not concentrate on this equilibrium type since for the class
} 
Since, in any coordination problem, beliefs are a critical element in determining equilibrium outcomes, we begin our analysis by describing the way that consumers form beliefs and showing how these beliefs affect the consumer purchase decision. ${ }^{11}$ Then, we examine a firm's profit maximization problem and characterize equilibrium advertising behaviors for firms and equilibrium beliefs for consumers.

\subsection{Beliefs and the Consumer Purchase Decision}

As described above, an individual consumer's purchase decision depends on that individual's beliefs about which, if either, variety will exceed the threshold purchase level. These beliefs are based on three elements: i) the individual's assessment of how advertising rates affect aggregate purchases - the coordination role of advertising, ii) what messages, if any, the individual observed and iii) observed prices. Because no consumer observes either firm's advertising rate, each consumer must form beliefs about both firms' rates based on observed prices and what message was observed (or not) from each firm. Using this information and an assessment of how joint advertising rates affect which variety exceeds the threshold purchase level (recall that both cannot), each consumer makes a purchase decision.

To make this process precise, we define for each consumer a joint assessment, J. Essentially, the joint assessment specifies two elements: i) the consumer's expectation about each firms' choice of advertising strategies; ii) for each realization under the expected strategies, the consumer's assessment about which, if either, variety exceeds threshold purchase levels. We define three possible threshold outcomes: (1) purchases of variety 1 are above the threshold but those of variety 2 are not, (2) purchases of variety 2 are above the threshold but those of variety 1 are not and (0) purchases of neither variety are above the threshold. A joint assessment then might specify that, if the firms set prices $\left(p_{1}, p_{2}\right)$, the pair $\left[\widetilde{a}_{1}\left(p_{1}\right), \widetilde{a}_{2}\left(p_{2}\right)\right]$ is of products that we are interested in, advertising competition involves both firms engaging in advertising.

${ }^{11}$ Beacuse no consumer observes either firm's advertising rate, the game here is one of imperfect information. Consumer beliefs must, therefore, be specified in order to characterize the set of equilibria. 
a possible advertising reach outcome and that, under this outcome, threshold outcome 1 occurs. A formal definition of the joint assessment is provided in the Appendix. For simplicity, we assume that all consumers share a common joint assessment.

Each consumer either receives a message from firm $i$ or does not, yielding a message outcome for the consumer. For any consumer, $k$, there are four possible message outcomes: observed a message from neither firm, $\alpha_{k}=(0,0)$; observed a message from firm 1 but no message from firm $2, \alpha_{k}=(1,0)$; observed a message from firm 2 but no message from firm $1, \alpha_{k}=(0,1)$; observed a message from both firms, $\alpha_{k}=(1,1)$.

Beliefs for consumer $k$ are a pair, giving the probabilities that threshold outcome 1 occurs and that threshold outcome 2 occurs. ${ }^{12}$ These beliefs depend on $k$ 's realization $\alpha_{k}$, the observed price pair, $p=\left(p_{1}, p_{2}\right)$, and the joint assessment, $J$. Formally, beliefs for consumer $k$ are given by $B_{k}\left[\alpha_{k}, p ; J\right]=\left\{\psi_{k 1}\left[\alpha_{k}, p ; J\right], \psi_{k 2}\left[\alpha_{k}, p ; J\right]\right\}$, where $\psi_{k 1}$ gives the probability that threshold outcome 1 occurs and $\psi_{k 2}$ gives the probability that threshold outcome 2 occurs.

Given beliefs, consumer $k$ compares the expected surplus from consuming variety 1, $E S_{k 1}$, to that from consuming variety $2, E S_{k 2}$ and purchases the variety that yields the higher surplus. The fraction of consumers with message outcome $\alpha_{k}$ and that purchase variety $1, x_{1}\left[J, \alpha_{k}, p_{1}, p_{2}\right]$, is given by the fraction of consumers with outcome $\alpha_{k}$ for whom:

$$
\begin{array}{lll}
E S_{k 1}\left[J, \alpha_{k}, p\right]=\psi_{k 1}\left[J, \alpha_{k}, p ; \widetilde{a}, \widetilde{q}\right] \bar{V}+\left(1-\psi_{k 1}\left[J, \alpha_{k}, p ; \widetilde{a}, \widetilde{q}\right]\right) \underline{V} & -p_{1} \quad-t k \geq \\
\psi_{k 2}\left[J, \alpha_{k}, p ; \widetilde{a}, \widetilde{q}\right] \bar{V}+\left(1-\psi_{k 2}\left[J, \alpha_{k}, p ; \widetilde{a}, \widetilde{q}\right]\right) \underline{V}-p_{2}-t(1-k) \quad=\quad E S_{k 2}\left[J, \alpha_{k}, p\right]
\end{array}
$$

The fraction of consumers with message outcome $\alpha_{k}$ and that purchase variety $2, x_{2}\left[J, \alpha_{k}, p_{1}, p_{2}\right]$, is given by $1-x_{1}\left[J, \alpha_{k}, p_{1}, p_{2}\right] .{ }^{13}$ Note that, if $\psi_{k 1}=\psi_{k 2}$ and $p_{1}=p_{2}$, then $x_{1}\left[J, \alpha_{k}, p_{1}, p_{2}\right]=$

\footnotetext{
${ }^{12}$ The complementary probability is the probability that neither variety exceeds threshold purchases (threshold outcome 0).

${ }^{13}$ We assume here that all consumers purchase one of the two varieties.
} 
$x_{2}\left[J, \alpha_{k}, p_{1}, p_{2}\right]=\frac{1}{2} \cdot{ }^{14}$ The fraction of the total population that purchases variety $i$ is the weighted sum of the $x_{i}\left[J, \alpha_{k}, p_{1}, p_{2}\right]$ over the four possible $\alpha_{k}$, with the weights given by the probabilities of each of the respective $\alpha_{k}$.

\subsection{The Firm Advertising Decision}

In making its advertising decision, firm $i$ chooses advertising rates $a_{i}$ to maximize expected profits, given choices by firm $j$ and consumer beliefs. Given consumer beliefs defined by some joint assessment, $J$, and choices of price, advertising rates and advertising probabilities for firm $j, p_{j}, a_{j}=\left\{a_{j 0}, \ldots, a_{j M}\right\}$, and $q_{j}=\left\{q_{j 0}, \ldots, q_{j M}\right\}$, firm $i$ 's expected profits at price $p_{i}$ and advertising rate $a_{i}$ are:

$$
\begin{aligned}
E \pi_{i}\left(p_{i}, a_{i} ; J, a_{j}, q_{j}, p_{j}\right)=p_{i} M\left\{q _ { j 0 } \left[a_{i}\left(a_{j 0} x_{i}\left[J,(1,1) ; p_{i}, p_{j}\right]+\left(1-a_{j 0}\right) x_{i}\left[J,(1,0) ; p_{i}, p_{j}\right]\right)\right.\right. \\
\left.+\left(1-a_{i}\right)\left(a_{j 0} x_{i}\left[J,(0,1) ; p_{i}, p_{j}\right]+\left(1-a_{j 0}\right) x_{i}\left[J,(0,0) ; p_{i}, p_{j}\right]\right)\right]+\ldots \ldots \\
\quad+q_{j M}\left[a_{i}\left(a_{j M} x_{i}\left[J,(1,1) ; p_{i}, p_{j}\right]+\left(1-a_{j M}\right) x_{i}\left[J,(1,0) ; p_{i}, p_{j}\right]\right)\right. \\
\left.\left.+\left(1-a_{i}\right)\left(a_{j M} x_{i}\left[J,(0,1) ; p_{i}, p_{j}\right]+\left(1-a_{j M}\right) x_{i}\left[J,(0,0) ; p_{i}, p_{j}\right]\right)\right]\right\}-F-c\left(a_{i}\right)
\end{aligned}
$$

Because demands have consumer beliefs about advertising rates and not the actual rate choice (recall that advertising rates are unobservable), firm $i$ 's revenue is a linear function of $a_{i}$. Marginal revenue with respect to $a_{i}$ is:

$$
\begin{aligned}
M R_{a_{i}}=p_{i} M\left\{x_{i}\left[J,(1,1) ; p_{i}, p_{j}\right] \sum_{a_{j m} \in a_{j}} q_{j m} a_{j m}+x_{i}\left[J,(1,0) ; p_{i}, p_{j}\right] \sum_{a_{j m} \in a_{j}} q_{j m}\left(1-a_{j m}\right)\right. \\
\left.\quad-x_{i}\left[J,(0,1) ; p_{i}, p_{j}\right] \sum_{a_{j m} \in a_{j}} q_{j m} a_{j m}-x_{i}\left[J,(0,0) ; p_{i}, p_{j}\right] \sum_{a_{j m} \in a_{j}} q_{j m}\left(1-a_{j m}\right)\right\}
\end{aligned}
$$

\footnotetext{
${ }^{14}$ Note that if we did not assume that all consumers purchase one unit, then market demand would equal $M$ and $x_{1}\left[J, \alpha_{k}, p_{1}, p_{2}\right]=x_{2}\left[J, \alpha_{k}, p_{1}, p_{2}\right]=.5 M$.
} 
which is independent of $a_{i}$. With variable cost, $c\left(a_{i}\right)$, increasing and strictly convex, firm $i$ 's expected profit is a strictly concave function of $a_{i}$ on the set $(0,1]$. The profit function has a discontinuity at $a_{i}=0$ since the fixed cost, $F$, is only incurred if $a_{i}>0$. Together, these observations imply that, if firm $i$ advertises at a positive rate, there is a unique rate $a_{i}^{*}$ that maximizes profits. In addition, profits may be higher or lower (or the same) at this rate than if the firm does not advertise at all.

The above result has immediate consequences for the structure of any equilibrium with advertising. In particular, since in equilibrium firm $i$ 's advertising rate must maximize expected profit given $j$ 's choices, $i$ 's equilibrium strategy can contain at most two advertising rates: $a_{i}=0$ and $a_{i}=a_{i}^{*}{ }^{15}$ Further, as the following result shows, there can be no equilibrium in which $a_{i}^{*}$ is chosen with probability 1 .

Lemma 1 There is no equilibrium in which $a_{i}$ is a singleton, $\widehat{a}_{i}$, with $\widehat{a}_{i}>0$.

What happens when a firm advertises with probability one is the following. Because no consumer observes the advertising rate and may or may not observe a message when the firm is advertising, failure to observe a message cannot disconfirm any belief that the firm is advertising at a positive rate. As a consequence, if the firm is surely advertising at some rate $\widehat{a}$, no message outcome can disconfirm a belief consistent with this behavior. Since advertising is costly, the firm can reduce its advertising rate, induce no alteration in consumer behavior and so increase profits.

The above results mean that equilibrium behavior by the firm is particularly simple. Either the firm chooses not to advertise at all, $a_{i}=0$, or it randomizes between not advertising and advertising at a unique positive rate: $a_{i}=0$ or $a_{i}=a_{i}^{*}$. In this latter case, the firm must set the same price, $p_{i}^{*}$, whether or not it advertises. If it did not, then price would

\footnotetext{
${ }^{15}$ Since consumer beliefs must be consistent with equilibrium advertising choices, the joint assessment, $J$, can be based on at most four advertising outcomes: $\left(\widetilde{a}_{1}=0, \widetilde{a}_{2}=0\right),\left(\widetilde{a}_{1}=0, \widetilde{a}_{2}=a_{2}^{*}\right),\left(\widetilde{a}_{1}=a_{1}^{*}, \widetilde{a}_{2}=0\right)$ and $\left(\widetilde{a}_{1}=a_{1}^{*}, \widetilde{a}_{2}=a_{2}^{*}\right)$.
} 
reveal whether the firm was advertising. In this case, the same argument as in the lemma would imply that advertising at rate $a_{i}^{*}>0$ could not be equilibrium behavior by the firm. ${ }^{16}$

These results are summarized in the following proposition.

Proposition 1 In any equilibrium, a firm advertises at at most two rates: $a_{i}=0$ and $a_{i}=a_{i}^{*}>0$, with $a_{i}^{*}$ being the unique (positive) maximizer of firm $i$ 's expected profits. If a firm advertises at the positive rate, then it must randomize between 0 and $a_{i}^{*}$. In this case, the equilibrium price choice, $p_{i}^{*}$, must be independent of the advertising choice.

\section{A Symmetric Advertising Equilibrium}

To gain more insight into the firms' equilibrium advertising behavior, we explore in this section the properties of what we call a symmetric advertising equilibrium. In this equilibrium, both firms randomize between not advertising and advertising at rate $a^{*}$, the latter being chosen with common probability $q^{*}>0$. Both firms also choose identical prices, $p^{*}$. In the equilibrium the joint assessment also treats firms symmetrically in assigning threshold outcomes to advertising rates. Since, by assumption, both firms cannot have sales above the threshold, symmetric treatment in the assessment requires that the 0 threshold outcome (neither variety over) be assigned to the advertising outcomes $\left(a_{1}=0, a_{2}=0\right),\left(a_{1}=a^{*}, a_{2}=a^{*}\right)$. For the other advertising outcomes, the joint assessment must assign threshold outcome 1 (variety 1 over and 2 not) to $\left(a_{1}=a^{*}, a_{2}=0\right)$ and threshold outcome 2 to $\left(a_{1}=0, a_{2}=a^{*}\right)$

\footnotetext{
${ }^{16}$ This result implies that the restriction imposed previously on consumers' price expectations (i.e., consumers expect advertising to be independent of price) is consistent with equilibrium behavior. Because beliefs off the equilibrium path are arbitrary, there will not be a unique equilibrium price in this case. The argument here is the same as in incomplete information games. If the firm's equilibrium strategy specifies a price $p_{i}^{*}$ but consumers observe a price $p_{i} \neq p_{i}^{*}$, then consumers' beliefs about both the firm's advertising rate and the threshold outcome cannot be derived from equilibrium behavior. A perfect Bayesian equilibrium places no constraints on beliefs in this case.
} 
if advertising is to occur in equilibrium. ${ }^{17} \mathrm{~A}$ formal definition of equilibrium is provided in the Appendix.

Under a symmetric advertising equilibrium, the values of $a^{*}$ and $q^{*}$ are defined by two conditions. First, for firm $i$ to be willing to randomize between advertising at rate $a^{*}$ and not advertising at all, it must be that $i$ obtains the same level of expected profits in each case given firm $j$ is following its equilibrium strategy. Expected profits for firm $i$ when choosing advertising level $a^{*}$ are:

$$
\begin{aligned}
E \pi_{i}\left(p^{*}, a=a^{*} ;\right. & \left.J_{S}, a^{*}, q^{*}, p^{*}\right)=p^{*} M\left\{q ^ { * } \left[a^{*}\left(a^{*} x_{i}\left[J_{S},(1,1), p^{*}\right]+\left(1-a^{*}\right) x_{i}\left[J_{S},(1,0), p^{*}\right]\right)\right.\right. \\
+ & \left.\left(1-a^{*}\right)\left(a^{*} x_{i}\left[J_{S},(0,1), p^{*}\right]+\left(1-a^{*}\right) x_{i}\left[J_{S},(0,0), p^{*}\right]\right)\right] \\
& \left.+\left(1-q^{*}\right)\left[a^{*} x_{i}\left[J_{S},(1,0), p^{*}\right]+\left(1-a^{*}\right) x_{i}\left[J_{S},(0,0), p^{*}\right]\right)\right\}-F-c\left(a_{i}\right) .
\end{aligned}
$$

Expected profits for $i$ from choosing not to advertise are:

$$
\begin{aligned}
E \pi_{i}\left(p^{*}, a=\right. & \left.0 ; J_{S}, a^{*}, q^{*}, p^{*}\right)=p^{*} M\left\{q^{*}\left(a^{*} x_{i}\left[J_{S},(0,1), p^{*}\right]+\left(1-a^{*}\right) x_{i}\left[J_{S},(0,0), p^{*}\right]\right)+\right. \\
& \left.\left(1-q^{*}\right) x_{i}\left[J_{S},(0,0), p^{*}\right]\right\}
\end{aligned}
$$

Since demand for variety $i$ in a symmetric equilibrium has $x_{i}\left[J_{S},(1,1), p^{*}\right]=x_{i}\left[J_{S},(0,0), p^{*}\right]$ $=.5<x_{1}\left[J_{S},(1,0), p^{*}\right]$ and $x_{i}\left[J_{S},(1,0), p^{*}\right]+x_{i}\left[J_{S},(0,1), p^{*}\right]=1$, the condition that the above two profit expressions must be equal reduces to the condition that:

$$
p^{*} a^{*} M\left(x_{i}\left[J_{S},(1,0), p^{*}\right]-.5\right)-F-c\left(a^{*}\right)=0 .
$$

The second condition is that $a^{*}$ yields firm $i$ higher expected profits than any other positive advertising rate, again given that firm $j$ is following its equilibrium strategy. If this condition is not satisfied, firm $i$ could deviate to some other positive advertising rate and

\footnotetext{
${ }^{17}$ As mentioned above we have chosen to focus only on equilibria in which both firms advertise, but of course asymmetric equilibria exist also. In asymmetric equilibria one firm never advertises while the other randomizes between not advertising and advertising at rate $a^{*}$.
} 
earn strictly higher profits. The condition defining $a^{*}$ as the profit maximizing advertising rate is:

$$
p^{*} M\left(x_{i}\left[J_{S},(1,0), p^{*}\right]-.5\right)-c^{\prime}\left(a^{*}\right)=0 .
$$

In the above conditions, the value of $x_{i}\left[J_{S},(1,0), p^{*}\right]$ is given by the fraction of consumers receiving message outcome $\alpha_{k}=[1,0]$ for whom

$$
\frac{1-q^{*}}{1-a^{*} q^{*}} \bar{V}+\frac{\left(1-a^{*}\right) q^{*}}{1-a^{*} q^{*}} \underline{V}-\underline{V} \geq 2 t k-t
$$

that is, the equilibrium value of $x_{i}\left[J_{S},(1,0), p^{*}\right]$ is given by

$$
x_{i}^{10}=\frac{\frac{1-q^{*}}{1-a^{*} q^{*}}(\bar{V}-\underline{V})+t}{2 t} .
$$

Note from this expression that $\partial x_{i}^{10} / \partial q^{*}<0$ and $\partial x_{i}^{10} / \partial a^{*}>0 .{ }^{18}$ Substitution of $x_{i}^{10}$ into (1) and (2) above yields 2 equations in two unknowns that solve for $a^{*}$ and $q^{*}$, the symmetric equilibrium advertising rate and advertising probability respectively.

As long as the fixed advertising cost, $F$, and the threshold outcome, $\bar{N}$, are not too large, it can be shown that, for given $p^{*}$, the pair $\left(q^{*}, a^{*}\right)$ satisfying (1) - (4) exists, is unique and generates purchases for firm $i$ that exceed the threshold $\bar{N}$ when $i$ is advertising and $j$ is not. The proof of this result is given in the Appendix. Because consumer beliefs when observing some price other than $p^{*}$ are not uniquely determined by our equilibrium notion, there is generally not a unique price outcome, $p^{*}$, and so not a unique outcome $\left(p^{*}, q^{*}, a^{*}\right)$. One might, however, use some selection rule $-p^{*}$ being the $p_{i}$ that maximizes $i$ 's expected profit given $\left(q^{*}, a^{*}\right)$ and price $p_{j}=p^{*}$ for firm $j$, for instance - to obtain a unique selection.

\footnotetext{
${ }^{18}$ These properties are based on the inference a consumer makes about the likelihood that firm $j$ is advertising when no message is heard from $j$. The larger is $q^{*}$, the more likely it is that $j$ is advertising but the consumer simply didn't hear the message. This inference makes $i$ less valuable to the consumer (since neither firm is believed to get over the threshold if both advertise) and so demand for $i$ falls. A similar analysis applies to the impact of an increase in $a^{*}$.
} 
Even without a selection rule to pin down $p^{*}$, the set of equilibria defined by (1) - (4) above have certain features in common that make predictions still possible. The simplest prediction is that advertising should be observed even for established products and for products that are not differentiated along any obvious quality dimension. In this way, the model provides an explanation for the observed advertising of products like those discussed in the Introduction. Under our explanation, these products are advertised because consumers who fail to see an ad for the product draw negative inferences about the likely value of the product. Such negative inferences provide the incentive for the producers to advertise and the advertising confirms the beliefs in equilibrium.

Next, note that if firm $i$ advertises and firm $j$ does not (i.e., $i$ 's randomization yields $a_{i}=a^{*}$ while $j$ 's yields $\left.a_{j}=0\right)$, then $i$ 's market share is $s_{i}^{a 0}=a^{*} x_{i}^{10}+\left(1-a^{*}\right) x_{i}\left[J_{S},(0,0), p^{*}\right]$ while $j$ 's is $s_{j}^{a 0}=a^{*}\left(1-x_{i}^{10}\right)+\left(1-a^{*}\right)\left(1-x_{i}\left[J_{S},(0,0), p^{*}\right]\right)$. Since $x_{i}\left[J_{S},(0,0), p^{*}\right]=.5$ while $x_{i}^{10}>.5$, it is immediate that firm $i$ has the larger market share. We have, then, that:

Result 1 : In an advertising equilibrium with realized advertising outcomes $a^{*}$ for firm $i$ and 0 for firm $j$, firm i's realized market share exceeds one-half and firm j's is below one-half.

Since, if either both firms advertise or neither do each firm has a market share of .5, this result means that firm $i$ 's market share is at least .5 if it advertises. If firm $i$ does not advertise, its realized market share is at most .5. If one thinks of observations on advertising and market share for varieties within a product category as being derived by repeated draws from the symmetric advertising equilibrium - a within product category panel data set this fact means that one will observe a positive relation on average between advertising and market share. This predicted relation is consistent with findings by Chintagunta and Vilcassim (1992) in a study of Coke and Pepsi.

A similar relation holds between observed advertising and profits. When firm $i$ advertises and $j$ does not, $i$ 's profits are given by $\pi_{i}^{a 0}=p^{*} M s_{i}^{a 0}-c\left(a^{*}\right)-F$. These realized profits are greater than $i$ 's expected profits from advertising, the latter being a weighted average of $\pi_{i}^{a 0}$ 
and the profits should $j$ also advertise: $E \pi_{i}^{a}=p^{*} M\left[\left(1-q^{*}\right) s_{i}^{a 0}+.5 q^{*}\right]-c\left(a^{*}\right)-F$. Under the equilibrium, $E \pi_{i}^{a}$ must be equal to $i$ 's expected profits from not advertising, $E \pi_{i}^{0}$, which, by an analogous argument, must be greater than $i$ 's realized profits should $j$ advertise and $i$ not. We have then:

Result 2 : In an advertising equilibrium with realized advertising outcomes $a^{*}$ for firm $i$ and 0 for firm $j$, firm i's realized profit is larger than firm $j$ 's realized profit.

In the sense of the above result, we have that observed advertising and profitability are positively related. This predicted relation is consistent with the findings of Erickson (1992) for Miller Brewing and Anheuser-Busch. Erickson finds over the period 1976-1990 that Anheuser-Busch advertised more than Miller and obtained larger profits net of advertising expenditures.

If we impose an equilibrium selection rule to pin down the value of $p^{*}$, additional results can be obtained. We impose selection by assuming that, in the neighborhood of equilibrium, consumer beliefs are independent of price. In this case, the price that firm $i$ sets is the one that maximizes expected profits given choices $\left(p^{*}, a^{*}, q^{*}\right)$ by firm $j$. This value of $p^{*}$ is given as:

$$
p^{*}=\arg \max _{p_{i}} E \Pi_{i}=q^{*} E \pi_{i}\left(p, a=a^{*} ; \widetilde{J}_{S}, a^{*}, q^{*}, p^{*}\right)+\left(1-q^{*}\right) E \pi_{i}\left(p, a=0 ; \widetilde{J}_{S}, a^{*}, q^{*}, p^{*}\right),
$$

where $\widetilde{J}_{S}$ incorporates the coordination structure in $J_{S}$ but does so independent of the price observation (at least locally). The solution to the above problem is $p^{*}=t$.

With this additional structure we can explore, among other things, the relations between market size, $M$, the fixed advertising cost, $F$, and firm advertising behavior. Note from (1) (4) that the value of $a^{*}$ is the one that minimizes average advertising cost; that is, $a^{*}$ solves $\left[F+c\left(a^{*}\right)\right] / a^{*}=c^{\prime}\left(a^{*}\right)$. The value of $q^{*}$ is determined by the condition $.5 M(\bar{V}-\underline{V})(1-$ $\left.q^{*}\right) /\left(1-a^{*} q^{*}\right)=c^{\prime}\left(a^{*}\right)$. Clearly, $a^{*}$ is independent of market size; on the other hand, $q^{*}$ is increasing in market size. 
Result 3 : The equilibrium advertising rate is independent of market size $-\partial a^{*} / \partial M=0-$ while the equilibrium advertising probability is increasing in market size $-\partial q^{*} / \partial M>0$.

This result implies that, on average, products having large markets are advertised more than those with small markets.

If we think of the symmetric advertising equilibrium as the data generating process that produces observed advertising outcomes across different product categories distinguished by market size, the above results can be used to generate cross-section predictions on advertising and profitability. Specifically, imagine that weekly (or monthly) advertising decisions in a cross-section of product categories are generated via the symmetric advertising equilibrium and that the observations for each product are aggregated to create annual product advertising expenditures and annual firm profits. Then annual advertising expenditures will be approximated by average advertising, $q^{*} a^{*}$, and annual profits by average profits.

From Result 3 we have that products in categories with larger markets will have larger observed annual advertising expenditures. Since average market share in equilibrium is .5, average profits are simply $E \pi=.5 t M-q^{*}\left[F+c\left(a^{*}\right)\right]$. Since both $q^{*}$ and $a^{*}$ are independent of $t$, expected profits are increasing with market size as long as $t$, the degree of product dissimilarity, is not too small (i.e., as long as consumers do not perceive the products as "too similar"). ${ }^{19}$ If $t$ is too small, the increased advertising activity in larger markets may more than dissipate the returns from increased market size and profits fall. The result is that, as long as a majority of the product category observations in the cross-section are for products that consumers perceive to be sufficiently differentiated horizontally, the cross-section will produce a positive but noisy correlation between advertising levels and profitability.

More typical in empirical studies is to examine the correlation between profitability and the advertising-sales ratio. Under the above interpretation of the cross-sectional observations,

\footnotetext{
${ }^{19}$ In particular, expected profits increase with maarket size as long as $t \geq(\bar{V}-\underline{V})\left(1-q^{*}\right)^{2} /\left(1-a^{*}\right)$. Since both $q^{*}$ and $a^{*}$ must be strictly less than 1 , there exists a well-defined value $\bar{t}$ such that expected profits are increasing in $M$ as long as $t \geq \bar{t}$.
} 
this ratio is given by $A / S=q^{*} a^{*} / .5 M t$. Whether $A / S$ increases or decreases with market size depends on the size of $q^{*}$; since $q^{*}$ depends on $M$, the impact of market size on $A / S$ depends ultimately on the size of $M$. As long as $q^{*}$ is not too large ( $M$ not too large), increases in market size lead to increases in the advertising-sales ratio. ${ }^{20}$ For very large values of $q^{*}$ (very large markets), $A / S$ decreases with market size. Therefore if the majority of observations in the cross-section either are i) products that consumers perceive as horizontally differentiated and with markets that are not too large, or ii) large market products that consumers perceive as very similar, then the cross-section will produce a positive correlation between profitability and the advertising-sales ratio. This outcome is precisely what is found in a number of crosssection studies on advertising and profitability (see, for instance, Comanor and Wilson (1967, 1974) and Porter $(1974,1976))$.

We can also examine how the form of the medium to which firms have access affects equilibrium advertising behavior. Since firms here have only one advertising medium available to them, this experiment involves an examination of how the costs of this particular medium affect the advertising equilibrium. ${ }^{21}$ All else equal, a medium with a larger fixed cost of advertising achieves minimum average cost at a larger advertising rate. From above, the equilibrium advertising rate, $a^{*}$, is the one that minimizes average advertising cost and so we have that ${ }^{22}$

Result 4 : The larger is the set-up cost, $F$, the larger is the advertising rate, $a^{*}$.

The rough prediction is that an advertising campaign in a particular medium (a magazine or a particular television program) and featuring a celebrity, say, will be run to reach a larger audience than would a campaign in the same medium that did not feature a celebrity.

\footnotetext{
${ }^{20}$ Specifically, the condition for $A / S$ to be increasing in $M$ is that $\frac{\partial q^{*}}{\partial M}>\frac{q^{*}}{M}$. Using the definition of $q^{*}$ from the text, we have that $A / S$ is increasing in $M$ as long as $1-2 q^{*}-a^{*} q^{* 2}>0$. Clearly a sufficient condition is that $q^{*} \leq .5$.

${ }^{21}$ For a model with multiple advertising media, see Clark and Horstmann (2003).

${ }^{22}$ In general, it cannot be determined whether $q^{*}$ increases or decreases.
} 
This larger audience reach might be achieved via a larger ad in the magazine or a longer commercial on television.

As more in the way of a pseudo-prediction, we also have that goods for which the common consumption aspect is more important - those with larger values of $(\bar{V}-\underline{V})$ - advertise with a higher probability.

Result 5 The equilibrium advertising rate, $a^{*}$, is independent of $(\bar{V}-\underline{V})$; the equilibrium advertising probability, $q^{*}$, is increasing in $(\bar{V}-\underline{V})$.

This result is a simple consequence of the fact that the cost-minimizing advertising rate is independent of the value of $(\bar{V}-\underline{V})$ and so only $q^{*}$ changes as $(\bar{V}-\underline{V})$ changes. The implication is that, for instance, fashion products (broadly defined) should be advertised more overall than, say, something like beverages where the common consumption aspect may be less important.

We note, finally, that here, as in many other models, the firms would benefit from a ban on advertising. In this model firms advertise because consumers believe that advertised goods are more likely high value goods. A unilateral reduction in the advertising rate reduces firm profits because there are fewer consumers with the information that the firm's variety is advertised. In essence, firms advertise because consumers who do not see an ad draw negative inferences about the value of the firm's product and so are less likely to purchase it. A ban on advertising credibly breaks these beliefs and allows firms to reduce advertising costs and increase profits. This finding is consistent with the empirical work done by Lambin (1976). In his study he finds limited support for the view that advertising increases industry demand, but does find that rival brand advertising negatively effects a firm's market share. 


\section{Discussion and Concluding Remarks}

In this paper we have attempted to provide an explanation for the observed advertising of products that are both established and have no obvious quality differentiation. A signaling explanation for advertising seems incompatible with these sorts of product characteristics. We argue that, to the extent that there are consumption externalities for these products - consumers care how many others also consume a given product - advertising can be understood as a coordination mechanism. Using a model in which individual consumers observe advertising messages but not any firm's total advertising rate, we show that advertising arises in equilibrium and serves to coordinate consumer purchases. In the equilibrium firms randomize between a single positive advertising level and no advertising. The model predicts that, when observed advertising levels differ, the firm that is observed to advertise obtains a greater market share and higher profits than the one that does not. The model is also able to produce, in a cross section, the positive correlation between profits and advertising/advertising-sales ratio that exists in the data.

There are several natural questions that arise in regards to our results. First, one of the basic predictions of our model is that firms randomize over advertising levels. A natural question, then, is whether we observe significant variability in advertising levels for a given product. This question is one that arises not just for our advertising model but for all coordination models of advertising. There are two answers to this question. One is that, even within product categories like beverages, we do find examples of significant advertising variability at the annual level. As an example, Adage (1995-1999) reports that advertising expenditures in the U.S. (in millions of dollars) for Diet Pepsi were:

$\begin{array}{cccccc}\text { date } & 1995 & 1996 & 1997 & 1998 & 1999 \\ \text { Diet Pepsi } & 10.7 & .2 & 19.7 & 13.9 & .8\end{array}$

A perhaps better answer is that one can interpret the model as describing the decision by the firm to engage in a particular advertising "spell", which may last a few weeks or 
possibly a month, within a particular medium that reaches a particular customer pool. This interpretation is the "pulse advertising" interpretation of the marketing literature in which firms "pulse" between positive advertising levels and zero advertising. ${ }^{23}$ Dubé, Hitsch and Manchanda (2003) document pulsing in the frozen entree market. Under this interpretation, one can observe large variation in advertising levels across weeks and markets while observing much less variation in total product adverting amounts at the annual level.

A second natural question, given that there are already coordination models of advertising, is how do the predictions of our model differ from those of existing models such as Bagwell and Ramey? Since our model set-up differs in various ways from that of Bagwell and Ramey, the easiest way to address this question is to ask how our results would differ were consumers able to observe advertising levels. Were advertising levels observable, then the equilibrium advertising strategy for a firm would be to randomize over some interval $[0, \bar{a}]$ of advertising levels, just as in Bagwell and Ramey. The only difference relative to Bagwell and Ramey would be that, because of the fixed cost of advertising, the mixing distribution would have an atom at 0 . The firm with the higher realized advertising level would provide utility (gross of price and transport costs) $\bar{V}$ while the firm with the lower advertising level would provide utility $\underline{V}$. Because relative advertising levels are observable, the firm with the lower realized advertising level sets a lower price than the firm with the higher realized advertising level. Specifically, the prices are $t-(\bar{V}-\underline{V}) / 3$ and $t+(\bar{V}-\underline{V}) / 3$ respectively; these prices yield respective market shares of $.5-(\bar{V}-\underline{V}) / 6 t$ and $.5+(\bar{V}-\underline{V}) / 6 t .{ }^{24}$

In some respects, the predictions of the model with observable advertising levels are similar to those of our model. Specifically, in both cases the firm with a higher observed advertising level earns higher profits than the firm with the lower observed advertising level.

\footnotetext{
${ }^{23}$ For a dicussion of pulse advertising, see Sasieni (1989).

${ }^{24}$ The equilibrium mixed strategy is defined by the probability mass at zero advertising, $\gamma$, the upper end of the advertising support, $\bar{a}$, and the distribution function over the interval $(0, \bar{a}], G(a)$. The equilibrium values are given by $\gamma=18 t F / V M(6 t+V), c(\bar{a})=2 V M / 3-12 t F /(6 t+V)$ and $G(a)=3 c(a) / 2 V M$, where $V=\bar{V}-\underline{V}$.
} 
Because firms are randomizing, on average (i.e., over a long enough time series) any specific firm's profits are independent of its advertising level. In a cross section of product categories in which variation is due to market size, both models are able to generate a positive correlation between profits and the advertising-sales ratio. In both cases, this correlation is noisy in that the advertising-sales ratio may decline with market size while profits increase.

In other respects, the models generate quite different results. With advertising levels unobservable, a specific product has at least weakly a higher market share when it advertises than when it does not. As a result, the time series shows that increased advertising at least weakly increases market share. With advertising levels observable, the market share for a specific product depends only on which product is advertised more. This means that the product's market share may actually rise when its advertising level falls and fall when its advertising level rises. As a result, the time series can actually show a negative relation between advertising and market share. ${ }^{25}$ Further, market share will move discontinuously with advertising levels: a small rise in advertising level has no impact on market share if it leaves the product as the less advertised one but raises market share by a discrete amount if it shifts the product to the more advertised one. In the one study of product level advertising and market share that we know of, Erickson found virtually no movement in relative market share between Coke and Pepsi over the period 1973-1980 even as the products switched rankings several terms in terms of relative advertising levels.

The models also generate very different predictions regarding the time series of prices and advertising levels. The model with unobservable advertising levels has that price does not vary with advertising, whereas the model with observable advertising levels has that product price rises when the product is the more heavily advertised one. ${ }^{26}$ Under our pulsing interpretation, the former model generates stable pricing with competition taking place through

\footnotetext{
${ }^{25}$ For a sufficiently long time series, average market share when the advertising level is low must be smaller than average market share when the advertising level is higher.

${ }^{26}$ The Bagwell-Ramey version has that the more heavily advertised product has a lower price.
} 
advertising while the latter model has extreme price variability. For products of interest to us - soft drinks, beer, bottled water, running shoes, credit cards - such extreme price variability seems inconsistent with observation. The model with unobservable advertising levels is consistent with the view that, for such products, prices are relatively sticky while competition occurs through non-price means.

The two versions of the model also differ with respect to the impact that the fixed advertising cost has on advertising rates. Whereas an increase in $F$ increases the advertising level in our model, it decreases the value of $\bar{a}$ in the model with observability and increases the probability mass on zero advertising. This means that, while our model predicts that a celebrity advertisement is seen more widely, the model with observability predicts that such an ad will be seen less widely on average.

We note two final points in closing. In deriving our results, we assume that consumer utility takes a simple threshold form and that consumers either observe an ad or do not. Neither of these assumptions are crucial to the main results. Both the result that a firm chooses at most 2 advertising levels, 0 and $a_{i}^{*}$, and cannot advertise at a positive level with probability one rely solely on the assumption that $i$ 's advertising level is not observable. This fact implies that demand for $i$ 's product depends on consumer beliefs about $i$ 's advertising level but is independent of $i$ 's actual choice of advertising level. This feature of demand is what generates the above results.

Finally, our model assumes a single advertising technology when, in fact, firms have access to numerous advertising media. A natural question is whether some advertising technologies are more effective at coordinating consumer purchases than others. We often see celebrity endorsements of products such as soft drinks, athletic shoes, and clothing. In a world such as ours in which advertising communicates only stochastically - individuals may not observe a message even though the firm is advertising - a question is whether celebrities might be particularly effective communication technologies in that they coordinate better than alternative messages. This issue is a subject of on-going research. 


\section{Appendix}

\section{Definition of a joint assessment:}

To define an individual consumer's assessment, let the set $\widetilde{a}_{i}\left(p_{i}\right)=\left\{\widetilde{a}_{i 0}\left(p_{i}\right), \ldots, \widetilde{a}_{i M}\left(p_{i}\right)\right\}$ give the set of advertising rates that any given consumer believes occur with positive probability under firm $i$ 's advertising strategy should the consumer observe price $p_{i}$. Let $\widetilde{q}_{i}\left(p_{i}\right)=$ $\left\{\widetilde{q}_{i 0}\left(p_{i}\right), \ldots, \widetilde{q}_{i M}\left(p_{i}\right)\right\}$ be the set of probabilities associated with each of the advertising rates in $\widetilde{a}_{i} \cdot{ }^{27}$ We assume that the sets $\widetilde{a}_{i}, \widetilde{q}_{i}$ are the same for all consumers. This is without loss of generality along the equilibrium path since equilibrium conditions will require that every consumer's beliefs be consistent with the firms' strategies. Define an advertising outcome as any pair $\left(\widetilde{a}_{1, m}\left(p_{1}\right), \widetilde{a}_{2, n}\left(p_{2}\right)\right)$ with $\widetilde{a}_{1, m}\left(p_{1}\right) \in \widetilde{a}_{1}\left(p_{1}\right)$ and $\widetilde{a}_{2, n} \in \widetilde{a}_{2}\left(p_{2}\right)$. For any given advertising outcome, there are three possible coordination outcomes. They are: (1) purchases of variety 1 are above the threshold but those of variety 2 are not, (2) purchases of variety 2 are above the threshold but those of variety 1 are not and (0) purchases of neither variety are above the threshold. These are the three threshold outcomes.

With these definitions in place, we can define the consumer assessment of how advertising coordinates purchase decisions. Specifically, define a joint assessment for any given consumer as a function that maps advertising outcomes into threshold outcomes. Formally:

Definition 1 A joint assessment, $J$, is a map from $\widetilde{a}_{1}\left(p_{1}\right) \times \widetilde{a}_{2}\left(p_{2}\right) \rightarrow\{0,1,2\}$, assigning to each pair $\left(\widetilde{a}_{1, m}\left(p_{1}\right), \widetilde{a}_{2, n}\left(p_{2}\right)\right) \in \widetilde{a}_{1}\left(p_{1}\right) \times \widetilde{a}_{2}\left(p_{2}\right)$ one of the threshold outcomes: neither over (0), 1 over and 2 not (1), 2 over and 1 not (2).

Essentially, the joint assessment is a statement that the consumer believes, for instance, that if firm 1 advertises at rate $\widetilde{a}_{1, m}\left(p_{1}\right)$ and firm 2 at rate $\widetilde{a}_{2, n}\left(p_{2}\right)$ and the price outcome $\left(p_{1}, p_{2}\right)$ is observed, then firm 1's sales will exceed the threshold and firm 2's will not. Every consumer

\footnotetext{
${ }^{27}$ We assume here and in what follows that firms follow pure strategies in determining price. In order to avoid unnecessary complications, we also assume here that the price choice for each firm is independent of the advertising rate. As will be seen below, this pricing strategy is a necessary feature of equilibirum.
} 
has one such statement for every possible advertising rate pair and these statements define the sense in which advertising coordinates purchases.

\section{Proof of Lemma 1:}

Consider a proposed equilibrium in which firm $i$ advertises at rate $\widehat{a}_{i}>0$ with probability 1. For $J$ to be consistent with the equilibrium it must be that any variation in a consumer's assessment of which threshold outcome will arise is due to variation in firm $j$ 's advertising rate. Bayesian updating based on the message outcome then implies that a consumer's beliefs, $B$, about the threshold outcome are independent of whether or not that consumer heard a message from firm $i$. The reason is that equilibrium consistent updating requires that the consumer believe that $i$ is advertising at rate $\widehat{a}_{i}$ with probability 1 regardless of the message outcome. As a consequence, $x_{i}\left[J,(1,1) ; p_{i}, p_{j}\right]=$ $x_{i}\left[J,(0,1) ; p_{i}, p_{j}\right]=x_{i}\left[J, 1 ; p_{i}, p_{j}\right]$ and $x_{i}\left[J,(1,0) ; p_{i}, p_{j}\right]=x_{i}\left[J,(0,0) ; p_{i}, p_{j}\right]=x_{i}\left[J, 0 ; p_{i}, p_{j}\right]$. Firm $i$ 's expected profits are then given by $E \pi_{i}\left(a_{i} ; A_{j}^{*}, J\right)=p_{i}\left\{x_{i}\left[J, 1 ; p_{i}, p_{j}\right] \sum_{a_{j l} \in A_{j}^{*}} q_{j}\left(a_{j l}\right) a_{j l}\right.$ $\left.+x_{i}\left[J, 0 ; p_{i}, p_{j}\right] \sum_{a_{j l} \in A_{j}^{*}} q_{j}\left(a_{j l}\right)\left(1-a_{j l}\right)\right\}-F-c\left(a_{i}\right)$, which is decreasing in $a_{i}$. As a result, firm $i$ can deviate to some $a_{i}<\widehat{a}_{i}$ and increase its profits.

\section{Definition of a Symmetric Advertising Equilibrium:}

A symmetric advertising equilibrium is defined by a set $\left(p^{*}, a^{*}, q^{*}, J_{S}, B_{S}^{*}\right)$ such that, for $i=1,2$ :

1. $E \pi_{i}\left(p^{*}, a=0 ; J_{S}, a^{*}, q^{*}, p^{*}\right)=E \pi_{i}\left(p^{*}, a=a^{*} ; J_{S}, a^{*}, q^{*}, p^{*}\right)$

2. $a^{*}=\arg \max _{a>0} E \pi_{i}\left(a, p^{*} ; J_{S}, a^{*}, q^{*}, p^{*}\right)$

3. $E \pi_{i}\left(p^{*}, a=a^{*} ; J_{S}, a^{*}, q^{*}, p^{*}\right) \geq \pi^{0}=\max _{p} \pi_{i}\left(p, p^{*}, a^{*}, q^{*}\right)$, where $\pi^{0}$ are maximal profits given firm $j$ 's strategy and consumer beliefs that firm $i$ never gets over the threshold.

4. If consumer $k$ chose variety $i$, then $E S_{k, i}\left[J_{S}, \alpha_{k}, p^{*}\right] \geq E S_{k, j}\left[J_{S}, \alpha_{k}, p^{*}\right]$

5. The joint assessment, $J_{S}$, is given by:

$$
\text { If } p_{1}=p_{2}=p^{*} \text { and }
$$




i. $a_{1}=a^{*}$ and $a_{2}=0$
ii. $a_{1}=0$ and $a_{2}=a^{*}$
iii. $a_{1}=a^{*}$ and $a_{2}=a^{*}$
iv. $a_{1}=0$ and $a_{2}=0$ , then $\left\{\begin{array}{l}\text { firm } 1 \text { is over and } 2 \text { is not } \\ \text { firm } 2 \text { is over and } 1 \text { is not } \\ \text { neither firm is over } \\ \text { neither firm is over }\end{array}\right.$

6. Beliefs, $B_{S}^{*}$, are given by:

$$
\begin{aligned}
& \text { i. } B\left[J_{S},(0,0), p^{*} ; a^{*}, q^{*}\right]=\left\{\left(\frac{\left(1-a^{*}\right) q^{*}}{1-a^{*} q^{*}}\right)\left(\frac{\left(1-q^{*}\right)}{1-a^{*} q^{*}}\right),\left(\frac{\left(1-a^{*}\right) q^{*}}{1-a^{*} q^{*}}\right)\left(\frac{\left(1-q^{*}\right)}{1-a^{*} q^{*}}\right)\right\} \\
& \text { ii. } B\left[J_{S},(1,0), p^{*} ; a^{*}, q^{*}\right]=\left\{\left(\frac{\left(1-q^{*}\right)}{1-a^{*} q^{*}}\right), 0\right\} \\
& \text { iii. } B\left[J_{S},(0,1), p^{*} ; a^{*}, q^{*}\right]=\left\{0,\left(\frac{\left(1-q^{*}\right)}{1-a^{*} q^{*}}\right)\right\} \\
& \text { iv. } B\left[J_{S},(1,1), p^{*} ; a^{*}, q^{*}\right]=\{0,0\}
\end{aligned}
$$

7.Purchase outcomes are consistent with $J_{S}$; that is,

$$
\begin{aligned}
& x_{1}\left(J_{S}, p^{*}, a_{1}=a^{*}, a_{2}=0\right) \geq \bar{N} \geq x_{2}\left(J_{S}, p^{*}, a_{1}=a^{*}, a_{2}=0\right) ; \\
& x_{2}\left(J_{S}, p^{*}, a_{1}=0, a_{2}=a^{*}\right) \geq \bar{N} \geq x_{1}\left(J_{S}, p^{*}, a_{1}=0, a_{2}=a^{*}\right) ; \\
& x_{1}\left(J_{S}, p^{*}, a\right)=x_{2}\left(J_{S}, p^{*}, a\right)<\bar{N}, a=(0,0),\left(a^{*}, a^{*}\right) .
\end{aligned}
$$

Conditions for existence and uniqueness of a Symmetric Advertising Equilibrium

From $(1)$ - (4), the equations that define $\left(a^{*}, q^{*}\right)$ for some value $p^{*}$ are:

$$
\begin{aligned}
p^{*} M(\bar{V}-\underline{V})\left(1-q^{*}\right) / 2 t\left(1-a^{*} q^{*}\right) & =c^{\prime}\left(a^{*}\right) \\
p^{*} a^{*} M(\bar{V}-\underline{V})\left(1-q^{*}\right) / 2 t\left(1-a^{*} q^{*}\right) & =F+c\left(a^{*}\right) .
\end{aligned}
$$

Combining these two equations, we have that $a^{*}$ is determined by the condition

$$
\left[F+c\left(a^{*}\right)\right] / a^{*}=c^{\prime}\left(a^{*}\right)
$$

This condition specifies $a^{*}$ as the value of $a$ that minimizes average advertising cost; since $c(a)$ is strictly convex, this value is unique. As long as the value that minimizes average advertising cost is strictly between 0 and 1 , then $a^{*}$ is the unique advertising level. With $F>0$, the value of $a^{*}$ is strictly positive and will be less than 1 as long as $F$ is not too large. 
Given a unique value of $a^{*} \in(0,1)$, the value of $q^{*}$ can be solved for from the above equations. It is given by:

$$
q^{*}=\frac{p^{*} M(\bar{V}-\underline{V})-2 t c^{\prime}\left(a^{*}\right)}{p^{*} M(\bar{V}-\underline{V})-2 t a^{*} c^{\prime}\left(a^{*}\right)} .
$$

As long as $p^{*} M(\bar{V}-\underline{V})-2 t c^{\prime}\left(a^{*}\right)>0$, the value of $q^{*}$ is strictly between zero and one. In this case, the conditions above specify the unique Symmetric Advertising Equilibrium values, $a^{*}$ and $q^{*}$.

\section{References}

[1] Bagwell, Kyle and Ramey, Gary. 1994. "Coordination Economies, Advertising, and Search Behavior in Retail Markets". The American Economic Review. Vol. 84. 498517.

[2] Bental, Benjamin and Spiegal, Menaheim. 1995. "Network Competition, Product Quality, and Market Coverage in the Presence of Network Externalities." The Journal of Industrial Economics. Vol. 43. 197-208.

[3] Chintagunta, Pradeep K. and Vilcassim, Naufel J. 1992. "An Empirical Investigation of Advertising Strategies in a Dynamic Duopoly." Management Science. Vol. 38. 12301244.

[4] Chintagunta, Pradeep K. 1993. "Investigating the Sensitivity of Equilibrium Profits to Advertising Dynamics and Competitive Effects." Management Science. Vol. 39. 11461162.

[5] Chwe, Michael Suk-Young. 1998a. "Culture, Circles, and Commercials: Publicity, Common Knowledge, and Social Coordination." Rationality and Society. Vol. X. 47-75. 
[6] 1998b. "Believe the Hype: Solving Coordination Problems with Television Advertising." Unpublished Manuscript, Department of Economics, University of Chicago.

[7] . 1999. Culture, Coordination and Common Knowledge. Unpublished manuscript.

[8] Clark, C. R. and Hosrtmann, Ignatius. 2003. "Celebrity Endorsements." Mimeo.

[9] Comanor, William S. and Wilson, Thomas A. 1967. "Advertising, Market Structure and Performance." The Review of Economics and Statistics. Vol. 49. 423-440.

[10] 1974. Advertising and Market Power. Cambridge, MA: Harvard University Press.

[11] Dubé, J.-P., G. Hitsch and P. Manchanda. 2003. "An Empirical Model of Advertising Dynamics". Unpublished manuscript.

[12] Erickson, Gary M. 1992. "Empirical Analysis of Closed-Loop Advertising Strategies." Management Science. Vol. 38. 1738-1749.

[13] Hertzendorf, Mark. 1993. "I'm not a High-Quality Firm - But I Play One on TV". RAND Journal of Economics 24, 236-47.

[14] Horstmann, Ignatius and MacDonald, Glenn. 1994. "When is Advertising a Signal of Product Quality." Journal of Economics and Management Strategy. Vol.3. 561-584.

[15] Lambin, Jean Jacques. 1976. Advertising, Competition and Market Conduct in Oligopoly Over Time. New York, NY: American Elsevier Publishing Company, Inc.

[16] Neilsen Media Services 1991-1998. Annual Survey of Advertising Expenditures in Canada. 
[17] Nelson, Phillip. 1974 "Advertising as Information." The Journal of Political Economy Vol. 82. 729-753.

[18] Padmanabhan,V. and Rajiv, Surendra and Srinivasan, Kannan. 1997. "New products, upgrades, and new releases: A rationale for sequential product introduction." Journal of Marketing Research. Vol. 34. 456-472.

[19] Pastine, Ivan and Pastine, Tuvana. 1999a "Consumption Externalities, Coordination and Advertising". Mimeo 1999, forthcoming, International Economic Review.

[20] 1999b. "Coordination in Markets with Consumption Externalities: The Role of Advertising and Product Quality". Mimeo, 1999.

[21] Porter, Michael E. 1974. "Consusmer Behavior, Retailer Power and Market Performance in Consumer Goods Industries". The Review of Economics and Statistics. Vol. 56. 419436.

[22] 1999. Interbrand Choice, Strategy and Bilateral Market Power. Cambridge, MA: Harvard University Press.

[23] Sasieni, Maurice. 1989, "Optimal Advertising Strategies". Marketing Science 8, pp. $358-70$. 